\title{
sciendo

\section{Numerical Evaluation of Probability of Harmful Impact Caused by Toxic Spill Emergencies}

\author{
Yurii SKOB ${ }^{1 *}$, Mykhaylo UGRYUMOV ${ }^{2}$, Eduard GRANOVSKIY ${ }^{3}$ \\ ${ }^{1}$ N.E. Zhukovsky Kharkiv National Aerospace University "KhAI”, Chkalova street 17, \\ Kharkiv, 61000, Ukraine \\ ${ }^{2}$ V.N. Karazin Kharkiv National University "KhNU”, the Svobodi Square 4, Kharkiv, 61000, Ukraine \\ ${ }^{3}$ Scientific Center of Risk Investigations “Rizikon”, Sovetsky prospect 33-b, Severodonetsk, 93411, Ukraine
}

\begin{abstract}
The purpose of the work is to assess the degree of inhalation damage of a person exposed to the toxic cloud of liquefied gas evaporation from a spill spot of various shapes. The mathematical model of liquefied gas spill evaporation which arose as a result of accidental destruction of the storage capacity and further dispersion of the gas impurity in the atmosphere surface layer was developed. The computational technology for determining the fields of conditional probability of human inhalation damage by a toxic gas based on a probit analysis is developed. The mathematical model takes into account the flow compressibility, complex terrain, three-dimensional nature of the dispersion process, and the presence of toxic liquid substance evaporation from the arbitrary spill spot with varying intensity. The model allows obtaining space-time distributions of the toxic gas relative mass concentration and inhaled toxidosis which is necessary to determine the fields of the human damage probability based on the probit analysis. For different ellipticity of the hydrogen cyanide spill elliptical spot the fields of probability of human mortal damage are obtained and the influence of spot ellipticity on the scale of the consequences of an accident of this type is analysed. The developed technology allows carrying out automated analysis and forecasting in the time and space of the damage probability of a person exposed to the toxic gas as an indicator of the safety of the technogenic object.
\end{abstract}

Keywords - Gas mixtures; numerical methods for solving partial differential equations; exposure to harmful substances; pollution

\begin{tabular}{|lll|}
\hline Nomenclature & & \\
$\mathrm{X}, \mathrm{Y}, \mathrm{Z}$ & Coordinates of the right Cartesian system & - \\
$G_{\Sigma}, G_{i}, G_{p}$ & Total, individual and given evaporation intensities & $\mathrm{kg} / \mathrm{sec}$ \\
$Q$ & Relative mass concentration of impurity & $\%$ \\
$u, v, w$ & Components of the velocity vector & $\mathrm{m} / \mathrm{sec}$ \\
$p$ & Pressure of the gas mixture & $\mathrm{Pa}$ \\
$\rho$ & Gas mixture density & $\mathrm{kg} / \mathrm{m}^{3}$ \\
$\mu$ & Molar mass of dangerous substance & $\mathrm{kg} / \mathrm{mol}$ \\
$t_{1}, t_{2}$ & Start and finish time of the evaporation process & $\mathrm{sec}$ \\
$F$ & Area of the spill spot & $\mathrm{m}$ \\
$M$ & Mass of the spilled dangerous substance & $\mathrm{kg}$ \\
\hline
\end{tabular}

\footnotetext{
* Corresponding author.

E-mail address: y.skob@khai.edu
} 


\begin{tabular}{|lll|}
\hline$P_{s}$ & Pressure of saturated vapor of dangerous substance & $\mathrm{mmHg}$ \\
$\Delta H_{b}$ & Heat of evaporation of the liquid substance & $\mathrm{J} / \mathrm{kg}$ \\
$T_{a}, T_{b}$ & Air temperature and the boiling point of the liquid substance & $\mathrm{K}$ \\
$\Delta H_{b}$ & Heat of evaporation of the liquid substance & $\mathrm{J} / \mathrm{kg}$ \\
$D$ & Inhalation toxidosis & - \\
$P_{r}$ & Probit function for toxidosis & - \\
$P$ & Conditional probability of damage & $\%$ \\
$\omega$ & Ellipse compression coefficient or ellipticity & - \\
\hline
\end{tabular}

\section{INTRODUCTION}

Technological processes of modern industrial enterprises include the use, transportation and storage of liquefied toxic chemical (TC) [1]. Violation of the equipment operation rules [2] leads to its failures accompanied by TC emission into the atmosphere with the formation of toxic clouds [3]. One of the most dangerous types of anthropogenic accident is the destruction of a storage or transportation tank of liquefied gas with the formation of a spill spot [4]. The mass concentration of the toxic gaseous substance in the gas-air mixture characterizes the negative deviation from the normal chemical composition of air and, along with the exposure time, is a dangerous parameter for the personnel within the zone of an industrial accident.

Exposure of the industrial facility personnel to certain concentrations of TC forms an affecting factor - inhalation toxidosis [5]. Excess of the threshold values of toxidosis leads to social consequences - poisoning of various degrees of gravity and human victims. Therefore, the calculation of enterprise risk for such an accident is an important and relevant engineering and practical task [6].

The assessment of the technogenic accident effects includes the determination of the probability of damage to service personnel [7], which may be affected by TC, based on the mathematical modelling of the scattering of toxic impurities in the atmosphere [8], [9] (Fig. 1). Such an approach can be used to assess the environmental safety of new industrial technologies [10], [11] along with an assessment of their economic efficiency [12].

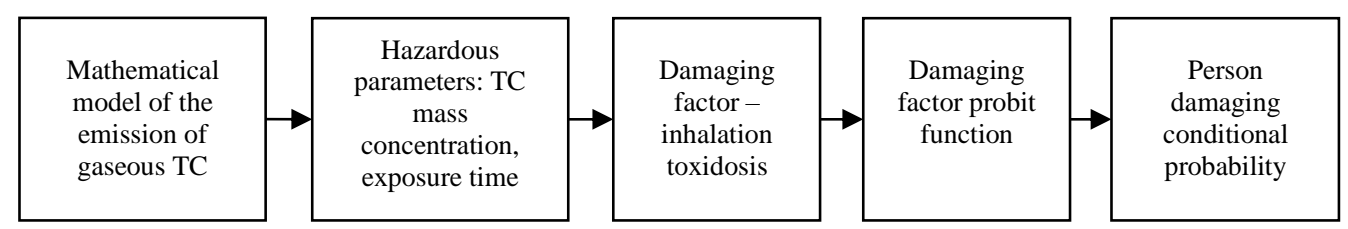

Fig. 1. Scheme of probabilistic assessment of the consequences of an accident.

Mathematical modelling of the physical processes of release and dispersion of harmful impurities in the surface layer of the atmosphere allows us to predict the fields of mass concentration of TC [13], to determine the inhalation toxidosis and the probability of damage to the maintenance personnel [14]-[16].

All models of mixture movement in the atmospheric surface layer can be divided into four main groups, which are distinguished by complexity and mathematical description [17]. The group of the simplest models uses an empirical approach [18], [19]. The group of models of intermediate 
complexity includes integral [20] and shallow layer models [21]. Lagrangian particle trajectory models [22] and Lagrangian puff dispersion models [23] form an advanced group. The Sophisticated group is formed by Computer Fluid Dynamics (CFD) models: Reynolds-Averaged Navier-Stokes (RANS) models [24], Large Eddy Simulation (LES) models [25] and Direct Numerical Simulation (DNS) models [26]. The most adequate description of the physical processes of mixing non-reactive gases with air and the further propagation of the mixture in open space is possible only with the use of a system of nonstationary Navier-Stokes equations for compressible gas. The limited capabilities of modern computers do not allow us to effectively implement a direct numerical solution of these equations [27]. At present, numerical modelling of turbulent flows is carried out by solving the Navier-Stokes equations averaged over the ReynoldsFavre complemented by a turbulence model [28], [29]. However, most models of turbulence do not describe the different types of flows with the same degree of adequacy. This is especially true for flows with intensive separations and/or high temperature gradients. Therefore, there is a need to build new models for numerical simulation of such flows.

In addition, some of the modern models are stationary [30], other methods of estimating pollution are based only on a deterministic approach [31], [32], and with the probabilistic approach to determining the consequences of damage to service personnel on the basis of a probit analysis, the probability dependence of the probit function in tabular form is used for expert analysis [15]. This does not allow us to apply this approach in an automatic mode in the computer system to obtain non-stationary fields of affecting factors and probability of damage and requires the improvement of computing technology.

The purpose of this work is to develop an adequate mathematical model of the processes of evaporation of a toxic impurity from the surface of a spot of a spillage of various forms as a result of an industrial accident, formation of a toxic cloud and its further distribution in the surface layer of the atmosphere in order to obtain space-time fields of the damaging factor of inhaled toxidosis and human damage probability based on probit analysis.

\section{Mixture Distribution Problem Statement}

Let's consider the formation and movement of the gas mixture at the open industrial site, where the accidental destruction of the storage tank of liquefied gas occurred (Fig. 2). The calculated domain is a parallelepiped with rectilinear generators located in the right Cartesian coordinate system $(\mathrm{X}, \mathrm{Y}, \mathrm{Z})$ with a base in the $\mathrm{XOZ}$ plane (the $\mathrm{Y}$ axis is oriented in the direction opposite to the action of the Earth gravity forces). The calculated area is divided into spatial cells. Under the influence of the environment, the liquefied gas evaporates from the spill spot and enters the atmosphere surface layer with a total intensity $G_{\Sigma}$. Fresh air flows with the wind speed through the entrance face of the calculated domain, mixed with the impurity, forming a gas-air cloud with a mass concentration $Q$.

To simplify the mathematical model and accelerate computing, we assume that the physical processes of the transition of a substance emitted into the surface layer from the liquid state into the gaseous phase pass instantaneously and in an infinitely thin layer. This assumption somewhat hardens the calculations, but in general allows an adequate description of the process of entering the gas admixture into the air of the surrounding space. 


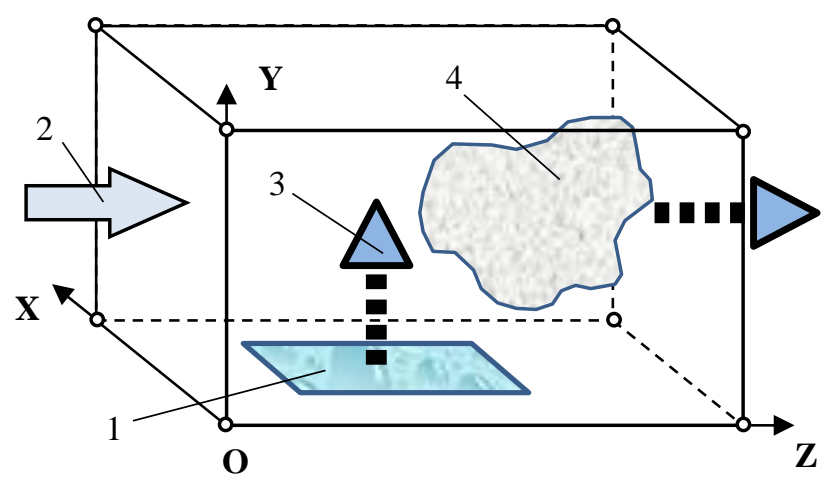

Fig. 2. Technogenic accident scheme: 1 - spill spot; 2 - fresh air; 3 - an admixture; 4 - gas-air cloud.

The flow of the gas mixture in the calculated region will be determined by the parameters of the ambient atmosphere, the area and shape of the spill spot, the parameters of the evaporated gas admixture coming into the atmosphere. At some point in time, the evaporation may stop and there will be no impurity in the area.

\section{Methods ANd Procedures}

\subsection{Basic Equations of the Mathematical Model}

It is assumed that the main factor influencing the physical processes under consideration is convective transfer of mass, momentum and energy. Therefore, it is sufficient to use the simplified Navier-Stokes equations that are obtained by dropping the viscous terms in the equations of gas mixture motion (Euler approach with source terms) [14].

The calculated area is divided into spatial cells, and the dimensions of the faces are selected in accordance with the characteristic size of the features of the calculated area (the roughness of the streamlined surface, the dimension of the streamlined objects).

The complete system of equations describing the nonstationary three-dimensional flow of a twocomponent gas mixture in this formulation, boundary and initial conditions, numerical solution algorithm and numerical method for synthesizing solutions of this class of problems is presented in the paper [15].

\subsection{Evaporation Simulation}

As a result of the sampling of the calculated area, the surface of the spill spot is also split into a series of finite-difference cells on the ground in the XOZ plane (Fig. 3(a)). In the case of a uniform decomposition in the direction of the axes OX and OZ, the faces of the "evaporating" cells are the same. Assuming the uniformity of the flow from the spill spot, it can be determined the individual prescribed gas flow for each of the "evaporating" cells $G_{i}=G_{\Sigma} / k$, where $k$ is the number of cells adjacent to the liquefied gas spill spot. 


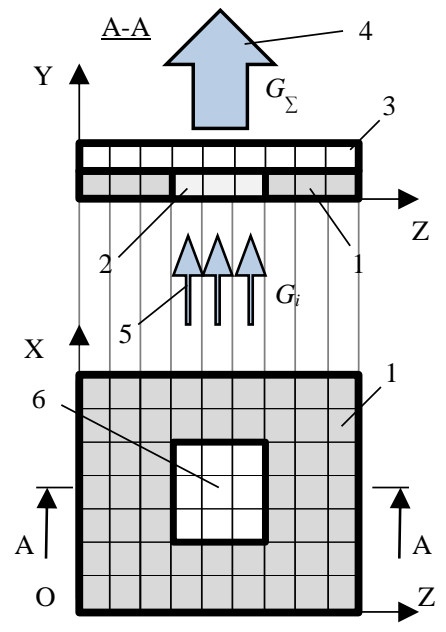

(a)

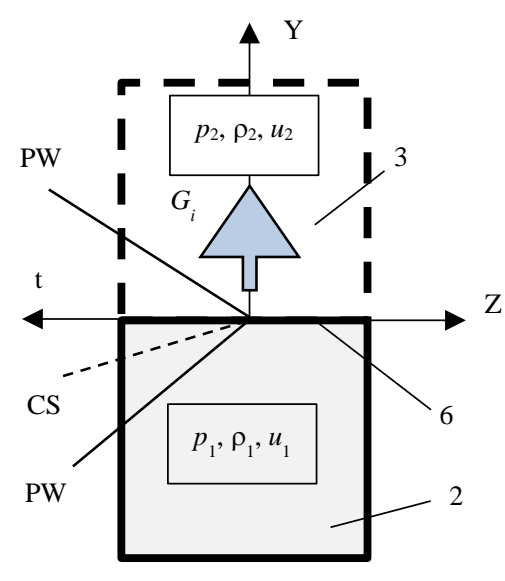

(b)

Fig. 3. The calculation scheme for determining the gas evaporation rate (a - discretization of the spill spot; b - evaporation scheme): 1 - the earth; 2 - fictitious spill spot cells; 3 - atmospheric cells; 4 - total gas flow; 5 - one cell gas flow; 6 - the "spill spot - air" boundary.

Suppose there is a gas medium for which the thermodynamic quantities of pressure $p$, density $\rho$, and internal energy of mass unit $\varepsilon$ obey the state equation. Assume that at the initial moment $t$ for the "down" half-space $\mathrm{x}<0$ the medium is characterized by the values of the parameters $p_{1}, \rho_{1}$, $u_{1}$, and for the "up" half-space $\mathrm{x}>0$ by the values of $p_{2}, \rho_{2}, u_{2}$ (here $u$ is the component of the velocity vector in the direction of the coordinate $\mathrm{x}$, and its other components are zero) (Fig. 3(b)).

Solving the discontinuity breaking problem on the face of a finite-difference cell adjacent to a spill spot, we can determine the density $R$ and the velocity $U$, and hence the individual gas flow $G_{i}$ through the considered face. Using the iteration method, it can be determined the pressure $p_{2}$ in such a way that the calculated gas flow rate $G_{i}$ differs from the given $G_{p}$ by a predetermined small value $\varepsilon$ (Fig. 4).

\subsection{Interpolation of the Evaporation Intensity Function}

When simulating the evaporation from a spill spot, the intensity of the "release" of the gas phase impurity into the atmosphere is usually assumed to be constant $G_{p}=$ const. If there is a total mass $m$ of the spilled liquid and the time $t_{1}$ of the beginning and $t_{2}$ of the end of the evaporation process, then the current evaporation intensity can be found from this relation:

$$
G_{p}=m /\left(t_{2}-t_{1}\right) .
$$




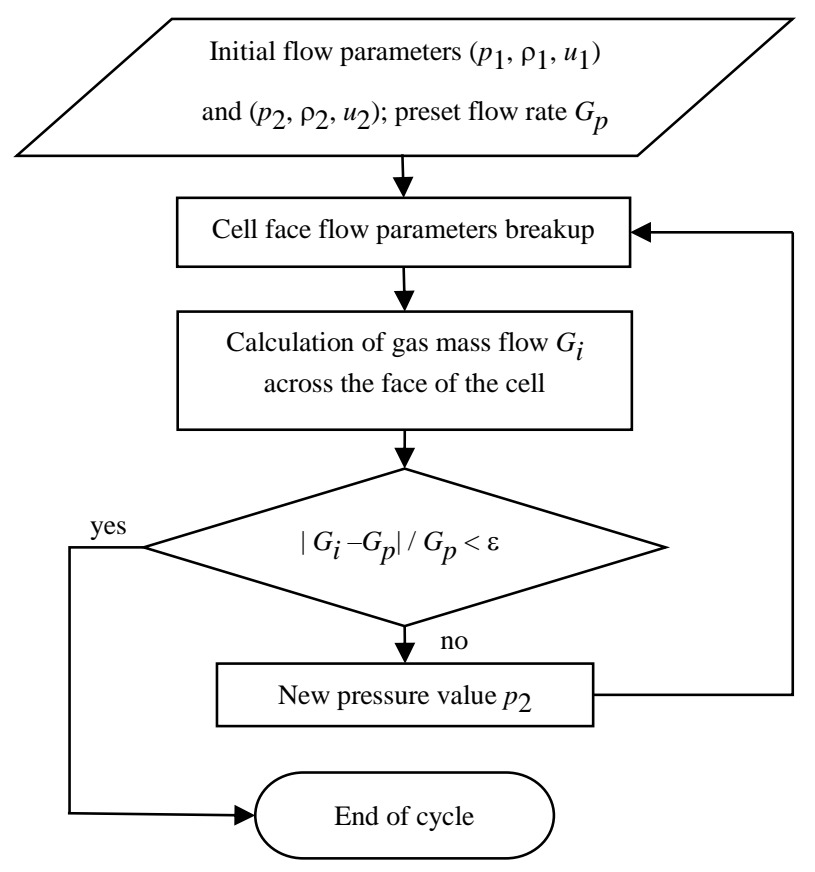

Fig. 4. Iterative algorithm for determining pressure $p_{2}$ at the current time of the evaporation process.

The area of the spill spot $F\left(\mathrm{~m}^{2}\right)$ can be determined by the following equation:

$$
F=\frac{M^{l}-M^{g}-M_{e}^{l}}{0.05 \rho_{l}},
$$

where

$\rho_{l} \quad$ Density of liquid hazardous substance, $\mathrm{kg} / \mathrm{m}^{3}$;

$M^{1} \quad$ Total mass of spilled liquid dangerous substance, $\mathrm{kg} / \mathrm{m}^{3}$;

$M^{g} \quad$ Mass of hazardous substance passing into the gas phase into the primary cloud with instantaneous boiling of superheated dangerous substance, $\mathrm{kg}$;

$M_{e}^{l} \quad$ Mass of dangerous substance, passing into an aerosol in the primary cloud, $\mathrm{kg}$.

The evaporation intensity $(\mathrm{kg} / \mathrm{sec})$ from the surface of the spill spot and the gas flow in the secondary cloud formed at the evaporation stage from the spot is determined by the Eq. (3) [33]:

$$
q^{e}=F \sqrt{\mu} 10^{-6}\left(5.38+4.1 u_{0 e f}^{e}\right) P_{s}
$$

where

$\mu \quad$ Molar mass of dangerous substance, $\mathrm{kg} / \mathrm{mol}$;

$u_{0 e f}^{e} \quad$ Initial effective velocity of the secondary cloud formed at the stage of evaporation from the spill spot, $\mathrm{m} / \mathrm{s}$; 
$P_{\mathrm{s}} \quad$ Pressure of saturated vapor of a dangerous substance at air temperature, $\mathrm{mmHg}$, which can be determined by the equation:

$$
P_{s}=760 \exp \left[\frac{\Delta H_{b} \mu\left(\frac{1}{T_{b}}-\frac{1}{T_{a}}\right)}{R}\right],
$$

where

$T_{\mathrm{a}} \quad$ Air temperature, $\mathrm{K}$;

$T_{b} \quad$ Boiling point of a liquid hazardous substance under environment pressure $P_{0}$ (under normal conditions is assumed to be equal $101325 \mathrm{~Pa}$ ), K;

$\Delta H_{b} \quad$ Heat of evaporation (boiling) of a liquid hazardous substance, $\mathrm{J} / \mathrm{kg}$.

\subsection{Probabilistic Safety Assessment}

As a result of modelling of toxic gaseous impurity distribution in the atmosphere, it is possible to obtain the functions of change in time and space of impurity mass concentration $Q$, and evaluate the degree of TC hazard exposure on the human (Fig. 1).

Consider the computational technology to determine the damage probability. Suppose that the integral power of influence $t$ is random, satisfying the normal distribution law with a mathematical expectation equal to 5 and a dispersion equal to 1 . In this case, the damage probability $P$ (measured in parts of the unit 1) can be estimated by the following equation:

$$
P=\frac{1}{\sqrt{2 \pi}} \int_{-\infty}^{P r} e^{-\frac{1}{2}(t-5)^{2}} \mathrm{~d} t .
$$

On the other hand, the integral degree of influence $t$ can be estimated using the regression equation $t=a+b f(\vec{x})$, where $\vec{x}=\left\{x_{k}\right\}$ are the quantitative estimates of the damaging factors, and $a, b$ are the coefficients of the regression equation.

Generally, in engineering practice, the damage probability evaluation is performed visually using its tabular dependence from the probit function of the affecting factor [34].

It is not convenient and does not allow the use of this apparatus in the integrated computerbased system for assessing technogenic safety. Therefore, in order to automate this process a piecewise-cubic Hermitian interpolating spline [35] is used (Fig. 5).

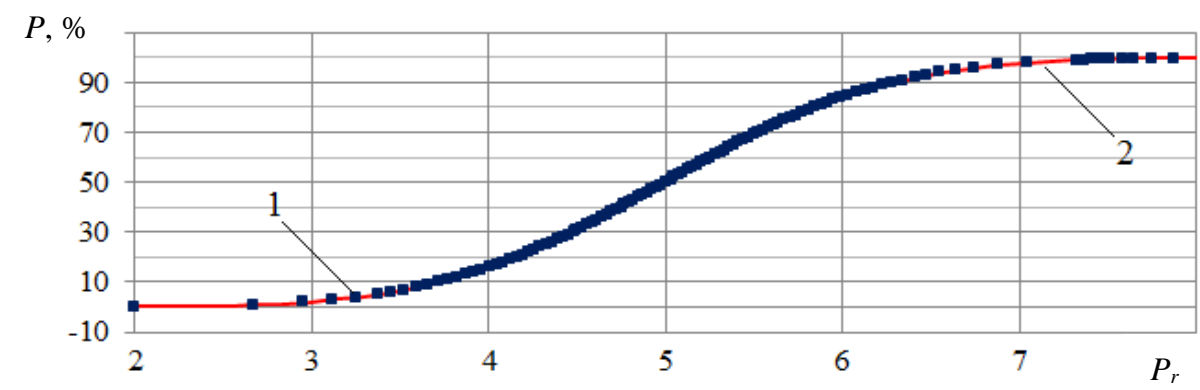

Fig. 5. Dependence "damage probability - probit function": 1 - table function; 2 - interpolation spline. 
Setting the upper limit of the integral (5) (probit-function $P_{r}=\left.t\right|_{x}$ ), it can be determined the damage probability. In the case of TC exposure, the main damaging factor is the inhalation toxidosis $D$ - the integral over time of TC concentration in the air:

$$
D=\int_{0}^{\left.\tau_{\exp }\right\rfloor} Q^{n} \mathrm{~d} \tau
$$

where

$\tau_{\exp } \quad$ Exposure time (time during which the toxidosis is inhaled), sec;

$Q \quad$ Space-time value of TC mass concentration, ppm;

$n \quad$ Table coefficient (for example, for cyanide hydrogen $n=1$ ).

The probit function for a lethal damage of a person due to the effect of the poisonous chemical inhalation in the general case is determined by the equation:

$$
P_{r}=A+B \ln (D)
$$

where $A$ and $B$ are the table semiempirical coefficients (for cyanide hydrogen $A=-37.98, B=-3.7$ and $\mu=27$ ).

\section{RESUlts}

The proposed algorithm and the method for calculating of the liquefied toxic gas evaporation intensity from the surface of a spill spot during the process of release of a gas admixture into the surface layer of the atmosphere is implemented as a subsystem of the research program system "Toxic Spill Safety" [36]. The model makes it possible to produce a three-dimensional analysis of the distribution of toxic gaseous impurities in time and space at a practically acceptable time and to make a forecast of the human fatalities due to the influence of toxic gas inhalation.

A modelling of the evaporation of $6925 \mathrm{~kg}$ of liquefied cyanide hydrogen (a toxic explosive substance with density $689 \mathrm{~kg} / \mathrm{m}^{3}$, molar mass $0.027 \mathrm{~kg} / \mathrm{mol}$, boiling point of $298.6 \mathrm{~K}$, and heat of evaporation $933 \mathrm{~kJ} / \mathrm{kg}$ ) was performed from a spill spot resulting from the destruction of a storage tank in the boundary of a settlement with large buildings (coefficient of power dependence for the approximation of air velocity in the atmospheric layer above the earth surface $k=0.4$ ) (Fig. 6).

The calculated area has dimensions $L_{\mathrm{x}} \cdot L_{\mathrm{y}} \cdot L_{\mathrm{z}}=85 \cdot 10 \cdot 85 \mathrm{~m}$ and the number of calculated cells along coordinate axes $85 \cdot 10 \cdot 85$. An ellipsoidal spill spot with semi-axis $a$ and $b$ is considered (Table 1) and the centre $C$ which is located in a distance of $X_{C}=16 \mathrm{~m}$ and $Z_{C}=16 \mathrm{~m}$ from the origin of the coordinates $\mathrm{O}$ (Fig. 6). The shape of the spot is characterized by the stretching factor along the direction of the wind (the ratio of the small and large semi-axis of the ellipse) $\omega=b / a$. This parameter is called an ellipse compression coefficient or ellipticity. Ellipses of three types with different ellipticity $\omega$, but have the same area $S$ (see Fig. 7(a)) are considered. Along the axis of the impurity dispersion zone symmetry three control points with coordinates $P_{0}(34.5 ; 34.5)$, $P_{1}(54.5 ; 54.5)$ and $P_{2}(74.5 ; 74.5)$ are located. 
TABLE 1. PARAMETERS OF ELLIPSE SPILl SPOTS

\begin{tabular}{lllll}
\hline Ellipse option & Semi-axis $a, \mathrm{~m}$ & Semi-axis $b, \mathrm{~m}$ & Ellipse area $S, \mathrm{~m}^{2}$ & Ellipticity $\omega$ \\
\hline 0 & 16.0 & 4.0 & 201.1 & 0.25 \\
1 & 8.0 & 8.0 & 201.1 & 1.0 \\
2 & 4.0 & 16.0 & 201.1 & 4.0 \\
\hline
\end{tabular}

The wind rises at a speed $3 \mathrm{~m} / \mathrm{s}$ at an angle $45^{\circ}$ to the axis $\mathrm{OZ}$ at the height $0.5 \mathrm{~m}$. In this case, the initial effective velocity of the secondary cloud formed at the stage of evaporation from the spill spot is $1.19 \mathrm{~m} / \mathrm{sec}$.

A spill spot is sampled by a finite-difference grid based on the principle: if the centre of the computing cell is inside the spot contour, the boundary condition of "evaporation" on this cell face of the will be exposed, otherwise - the "non-flow" boundary condition. The results of such a spill spot sampling for variant 1 of factor $\omega=1$ is presented on Fig. 7(b).

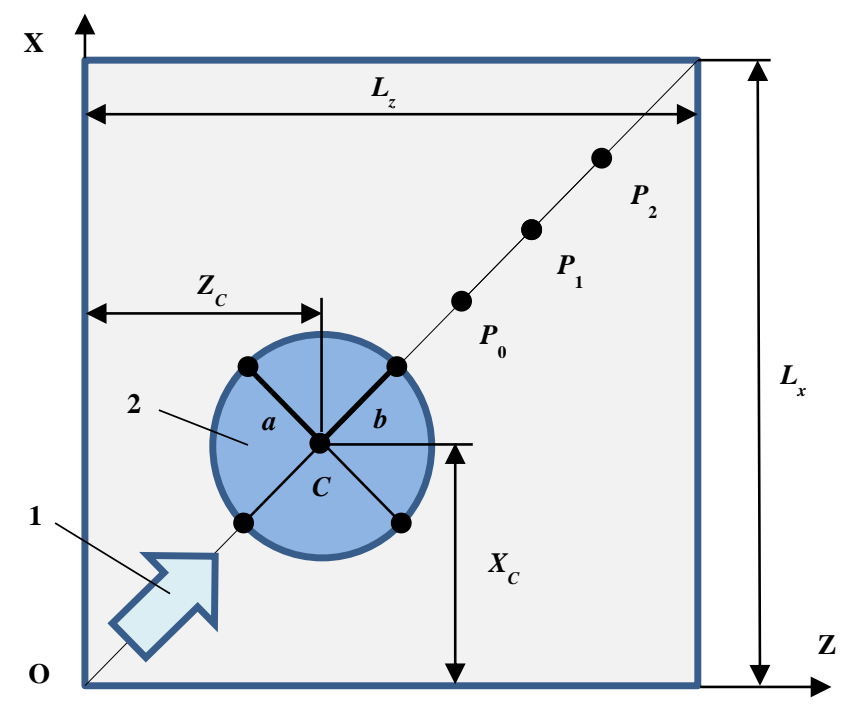

Fig. 6. Map of objects: $1-$ vector of wind speed; $2-$ spill spot; $P_{0}-P_{2}-$ control points.

If we ignore the mass of the gas fraction $M^{g}$ of the primary cloud formed as a result of the accidental destruction of the tank and take into account that the boiling point of the substance is higher than the ambient temperature (the mass of the dangerous substance passing into the aerosol into the primary cloud $M^{1}{ }_{e}=0$ ), according to the Eq. (2) the area of the spill spot is $201 \mathrm{~m}^{2}$, which corresponds to the magnitudes of the areas of the ellipses under consideration. Then, in accordance with Eq. (3), the intensity of the evaporation of cyanide hydrogen from the spill spot is $0.00106 \mathrm{~kg} / \mathrm{sec} / \mathrm{m}^{2}$. 


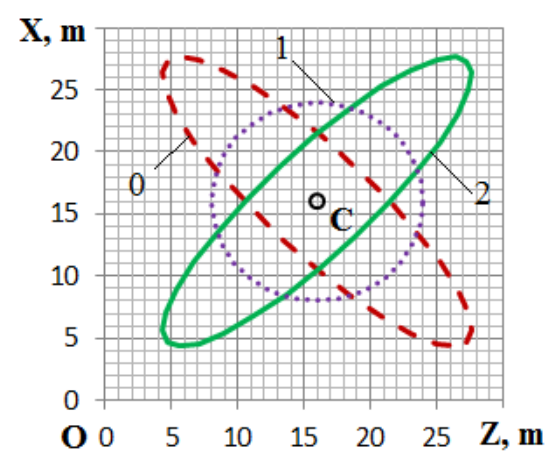

(a)

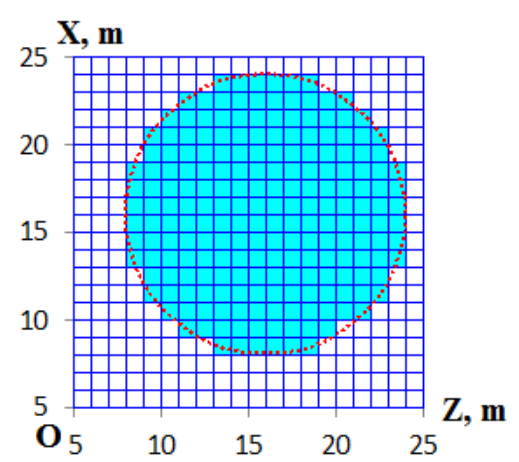

(b)

Fig. 7. Ellipsoidal spill spots: (a) different ellipticity shape $(0-$ variant $-\omega=0.25 ; 1-$ variant $-\omega=1.0 ; 2-$ variant $\omega=0.25$ ); (b) sample discretization of a spot variant 1 .

It is believed that the evaporation begins at the time $t_{1}=0 \mathrm{sec}$ and is forced to cease at the end of $t_{2}=5 \mathrm{sec}$, for example, by filling the spill spot with a special foam. The end time of the calculations is taken so that the gas-air toxic cloud has left the limits of the calculated area (approximately $20 \mathrm{sec}$ ).

Three variants of calculation are executed, each of which is characterized by the magnitude of the factor $\omega$ : 0 - variant with the least stretched ellipse $\omega=0.25 ; 1-$ option with a round spot $\omega=1 ; 2$ - option with the most stretched ellipse $\omega=4$. The analysis of the change in the fields of mass concentration of cyanide hydrogen is carried out in the plane of $\mathrm{XOZ}$ in the layer of computing cells on the ground. Fig. 8 shows a typical picture of the toxic substance distribution for different spot variants.

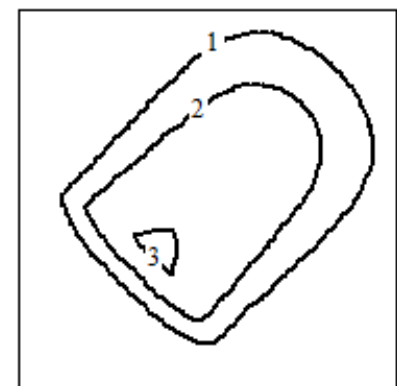

(a)

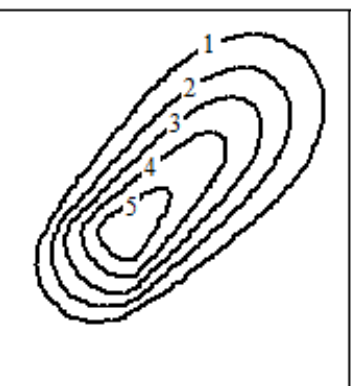

(b)

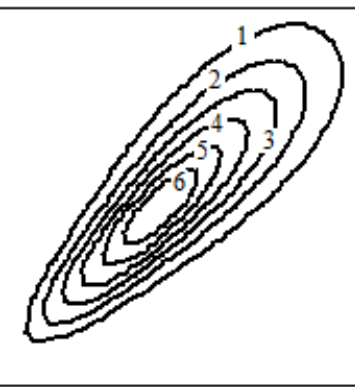

(c)

Fig. 8. Fields of toxic impurity relative mass concentration at time $t=5 \mathrm{~s}$ since the start of evaporation: (a) variant 0 , (b) variant 1 , (c) variant 2 (levels $1-6$ are the concentrations of $0.05,0.1,0.15,0.2,0.25,0.3 \%$, respectively).

The dynamics of changes in the impurities mass concentration at control points for a different form of spill spot is depicted on Fig. 9.

Non-stationary fields of cyanide hydrogen mass concentration can be considered as a space-time distribution of the dangerous parameter of the observed physical process. These data are used to calculate toxidosis, as a damaging factor, the probit function for a given toxic substance, and, consequently, the conditional lethal probability for an exposed person (Fig. 10). 


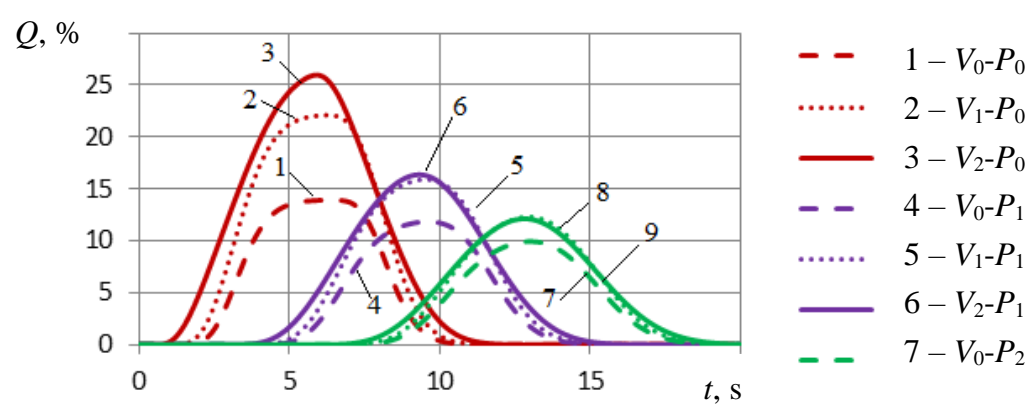

Fig. 9. Mass concentration history for different form spillage spot: $1-3-$ in the control point $P_{0} ; 4-6-$ in the control point $P_{1} ; 7-9-$ in the control point $P_{2}$.

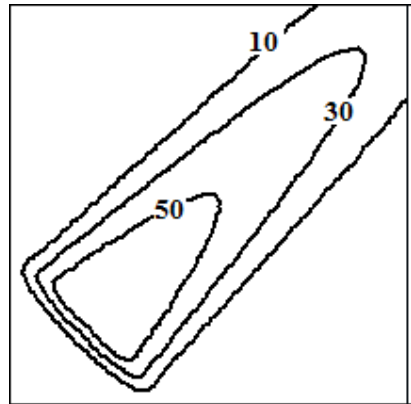

(a)

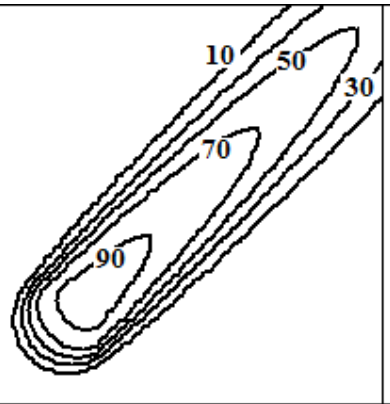

(b)

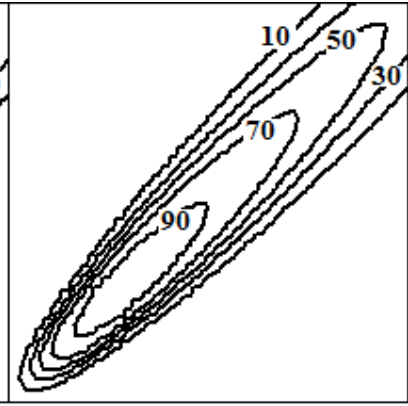

(c)

Fig. 10. The field of the lethal conditional probability (\%): (a) variant 0 , (b) variant 1 , (c) variant 2 .

For the safety analysis in control points a comparative diagram of the dependence of the lethal conditional probability from the shape of a spill spot is displayed (Fig. 11(a)). Another comparative characteristic of the danger of the considered process is the area $S_{50}$ occupied by a zone with a lethal conditional probability of $50 \%$ and above (Fig. 11(b)).

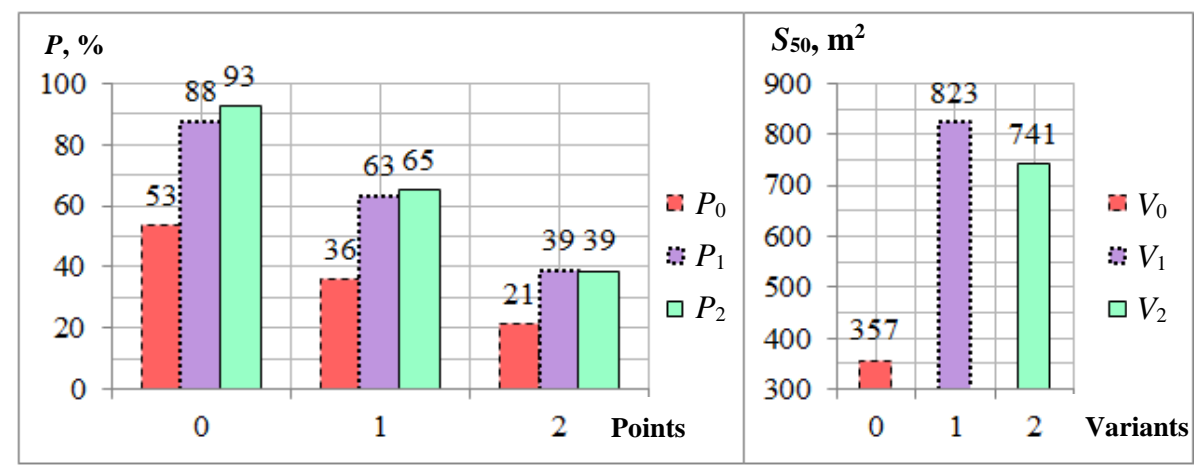

(a)

(b)

Fig. 11. Lethal conditional probability for: (a) different spill spots; b) dangerous area for different spill spots. 


\section{DISCUSSION}

The space-time analysis of the hydrogen cyanide mass concentration fields near the earth for spill spots with differently expanded ellipse (Fig. 8) allows us to see a typical picture of the distribution of a gaseous impurity with the maximum concentration core over a spill spot, the dispersion of a cloud along the wind direction with gradual decrease of concentration values, that is due to the turbulent mixing of impurity with clean air. After the evaporation ceases, the cloud freely leaves the calculated area, gradually dissipating.

This point of view is confirmed by the dynamics of the time variation in the mass concentration of the impurity at the control points, as shown in Fig. 9 for a various shapes of the spill spot. It is seen that each variant gives a typical picture of a gradual decrease in the maximum mass concentration magnitude as the cloud moves away from the epicentre of the evaporation. Moreover, the larger the magnitude of the factor $\omega$ of the spill spot, the greater the maximum mass concentration at the control point. This difference is gradually levelled as it moves away from the centre of the spot. The qualitative and quantitative analysis of lethal conditional probability fields presented on Fig. 10 makes it possible to draw a conclusion on the significant effect of the shape of the spill spot on the location and form of a dangerous area for a human being. The smaller the factor $\omega$ is with respect to the circular spot, the less the lethal conditional probability at the control point (Fig. 11(a)) and the characteristic area $S_{50}$ of the most dangerous zone with a lethal conditional probability more than $50 \%$ (Fig. 11(b)) are. With an increase in the factor $\omega$ relative to the circular spot, the trend of increasing the lethal conditional probability at the control point is maintained, but less significant, and the characteristic area $S_{50}$ even decreases somewhat, which can be explained by the narrower impurity density core of the in the cloud and by the more intense turbulent mixing with pure air.

Thus, the revealed features of the dispersion of a toxic impurity justify the need to consider the factor $\omega$ for the ellipsoidal shape of the toxic liquid spill spot during the analysis and forecast of the development of a technogenic accident of the type under consideration in order to develop the recommendations for reducing the risks of human lethal outcome.

\section{CONCLUSION}

On the basis of the developed mathematical model of processes of liquefied toxic gas evaporation with a given intensity from a spill spot of various forms and the dispersion of the impurity in the surface layer of the atmosphere, the spatial and time dependent distribution of the toxic gas mass concentration and inhalation toxidosis are obtained, necessary for determining the fields of lethal conditional probability in the area of the accident using probit analysis.

It was found that in the case of an ellipsoidal spot of a toxic substance evaporation, the spot shape (its ellipticity) relative to the wind direction significantly influences the scale of the accident consequences, and this circumstance must be taken into account at the stage of decision-making by the expert when analysing and forecasting the safety state and calculating the risks of possible accident type.

\section{REFERENCES}

[1] Andersson B., Andersson R., Hakansson L. Computational Fluid Dynamics for Engineers. New York: Cambridge University Press Publ., 2012.

[2] Zhang H.-D., Zheng X-P. Characteristics of hazardous chemical accidents in China: A statistical investigation. Journal of Loss Prevention in the Process Industries 2012:25(4):686-693. doi:10.1016/j.jlp.2012.03.001 
[3] Hughes Ph., Ferrett E. Introduction to Health and Safety at Work: The Handbook for the NEBOSH National General Certificate. Oxford: Butterworth-Heinemann, 2011.

[4] Nolan, D. Handbook of Fire and Explosion Protection Engineering Principles: for Oil, Gas, Chemical and Related Facilities $4^{\text {th }}$ ed. Gulf Professional Publishing, 2018.

[5] Hallenbeck W. H., Flowers R. E. Risk analysis for worker exposure to benzene. Environmental Management 1992:16(3):415-420. doi:10.1007/BF02400081

[6] Chrostowski P. C., Pearsall L. J., Shaw C. Risk assessment as a management tool for inactive hazardous materials disposal sites. Environmental Management 1985:9(5):433-441. doi:10.1007/BF01866342

[7] Levin S. A., et al. New perspectives in ecotoxicology. Environmental Management 1984:8(5):375-442. doi:10.1007/BF01871807

[8] Assael M. J., Kakosimos K. E. Fires, Explosions, and Toxic Gas Dispersions: Effects Calculation and Risk Analysis. New York: CRC Press Publ., 2010. doi:10.1201/9781439826768

[9] Huyen D. T. T., Tram L. T. B. Development of a Procedure for Evaluating the Impacts of the Accidental Emission of Hazardous Chemicals, Case Study in Ho Chi Minh City, Vietnam. Environmental Management 2019:63(4):486-494. doi:10.1007/s00267-017-0979-0

[10] Blumberga A., Timma L., Blumberga D. System Dynamic Model for the Accumulation of Renewable Electricity using Power-to-Gas and Power-to-Liquid Concepts. Environmental and Climate Technologies 2015:16(1):54-68 doi:10.1515/rtuect-2015-0012

[11] Vigants E., et al. Modelling of Technological Solutions to 4th Generation DH Systems. Environmental and Climate Technologies 2017:20(1):5-23. doi:10.1515/rtuect-2017-0007

[12] Bariss U., et al. System Dynamics Modeling of Households' Electricity Consumption and Cost-Income Ratio: a Case Study of Latvia. Environmental and Climate Technologies 2017:20(1):36-50. doi:10.1515/rtuect-2017-0009

[13] Truong S. C. H., et al. Accidental benzene release risk assessment in an urban area using an atmospheric dispersion model. Atmospheric Environment 2016:144:146-159. doi:10. 1016/j.atmosenv.2016.08.075

[14] Granovskiy E. A., et al. Numerical Modeling of Hydrogen Release, Mixture and Dispersion in Atmosphere. Proceedings of 1-st International Conference on Hydrogen Safety, Pisa, Italy, 2005. [Online]. [Accessed 24.02.2019]. Available: http://conference.ing.unipi.it/ichs2005/Papers/110021.pdf

[15] Skob Y. A., Ugryumov M. L., Granovskiy E. A. Mathematical modeling of hydrogen explosion consequences at fueling station. Proceedings of 7th International Conference on Hydrogen Safety, Hamburg, Germany, 2017. [Online]. [Accessed 12.03.2019]. Available: https://hysafe.info/wp-content/uploads/2017_papers/159.pdf

[16] Kim C. H., et al. Operational Atmospheric Modeling System CARIS for Effective Emergency Response Associated with Hazardous Chemical Releases in Korea. Environmental Management 2004:33(3):345-354. doi:10.1007/s00267-003-0030-5

[17] Markiewicz T. A review of mathematical models for the atmospheric dispersion of heavy gases. Part I. A classification of models. Ecological Chemistry and Engineering S 2012:19(3):297-314. doi:10.2478/v10216-011-0022-y

[18] Rogulski M. Indoor $\mathrm{PM}_{10}$ concentration measurements using low-cost monitors in selected locations in Warsaw. Energy Procedia 2018:147:137-144. doi:10.1016/j.egypro.2018.07.043

[19] Barisa A., Rosa M. Scenario analysis of $\mathrm{CO}_{2}$ emission reduction potential in road transport sector in Latvia. Energy Procedia 2018:147:86-95. doi:10.1016/j.egypro.2018.07.036

[20] Puttock J. S., et al. Dispersion models and hydrogen fluoride predictions. Journal of Loss Prevention in the Process Industries 1991:4(1):16-28. doi:10.1016/0950-4230(91)80003-D

[21] Folch A., Costa A., Hankin R. K. S. Twodee-2: A shallow layer model for dense gas dispersion on complex topography. Computers \& Geosciences 2009:35(3):667-674. doi:10.1016/j.cageo.2007.12.017

[22] Kopka P., Wawrzynczak A. Framework for stochastic identification of atmospheric contamination source in an urban area. Atmospheric Environment 2018:195:63-77. doi:10.1016/j.atmosenv.2018.09.035

[23] Burns D. S., et al. A simplified chemistry module for atmospheric transport and dispersion models: Proof-of-concept using SCIPUFF. Atmospheric Environment 2012:56:212-221. doi:10.1016/j.atmosenv.2012.03.067

[24] Merah A., Noureddine A. Reactive pollutants dispersion modeling in a street Canyon. International Journal of Applied Mechanics and Engineering 2019:24(1):91-103. doi:10.2478/ijame-2019-0006

[25] Arvidson S., Davidson L., Peng S.-H. Interface methods for grey-area mitigation in turbulence-resolving hybrid RANS-LES. International Journal Heat and Fluid Flow 2018:73:236-257. doi:10.1016/j.ijheatfluidflow.2018.08.005

[26] Lipatnikov A. N., Sabelnikov V. A., Poludnenko A. Y. Assessment of a transport equation for mean reaction rate using DNS data obtained from highly unsteady premixed turbulent flames. International Journal Heat and Mass Transfer 2019:134:398-404. doi:10.1016/j.ijheatmasstransfer.2019.01.043

[27] Galeev A. D., Starovoitova E. V., Ponikarov S. I. Numerical simulation of the formation of a toxic cloud on outpouring ejection of liquefied chlorine to the atmosphere. Journal of Engineering Physics and Thermophysics 2013:86(1):219228. doi:10.1007/s10891-013-0823-1

[28] Engeln-Müllges G., Niederdrenk K., Wodicka R. Numerik-Algorithmen: Verfahren, Beispiele, Anwendungen. Berlin: Xpert.press Publ., 2010. (in German) doi:10.1007/978-3-642-13473-9 
[29] Snegirev A. Y., Frolov A. S. The large eddy simulation of a turbulent diffusion flame. High Temperature 2011:49:690704. doi:10.1134/S0018151X11040201

[30] Sutthichaimethee P., Ariyasajjakorn D. Forecast of Carbon Dioxide Emissions from Energy Consumption in Industry Sectors in Thailand. Environmental and Climate Technologies 2018:22(1):107-117. doi:10.2478/rtuect-2018-0007

[31] Belyaev N. N., Koptilaya O. V. Kompiuternoe modelirovanie zagriazneniia okruzhaiushchei sredy pri razlive ammiaka. Dnipropetrovsk. Ekologia prirodokoristuvannia - Ecology and nature management, Transactions of IPPE NAN Ukraine. 2002:2:158-162. (in Russian)

[32] Slisane D., Blumberga D. Assessment of Roadside Particulate Emission Mitigation Possibilities. Environmental and Climate Technologies 2013:12(1):4-9. doi:10.2478/rtuect-2013-0009

[33] Matsak V. G., Khotsianov L. K. Gigienicheskoe znachenie skorosti ispareniia i davleniia para toksicheskikh veshchestv primeniaemykh v proizvodstve. Moscow: Medgiz, 1959. (in Russian)

[34] RD-03-26-2007. Metodicheskiye ukazaniya po otsenke posledstviy avariynykh vybrosov opasnykh veshchestv. (Methodological guidelines for the assessment of the consequences of accidental releases of hazardous substances.) Moscow: STC "Industrial safety", 2008:27(6):122.

[35] Knott G. D. Interpolating Cubic Splines. Boston: Birkhäuser Publ., 2012.

[36] Skob Y. A., Ugryumov M. L. Kompyuterna interaktyvna systema inzhenernoho analizu ta prohnozu "Toxic Spill Safety" dlya otsinky bezpeky pid chas avariynoho prolyttya toksychnoho zridzhenoho hazu. (Computer Interactive System "Toxic Spill Safety" of Engineering Analysis and Forecast for Safety Assessment of Accidental Spillage of Toxic Liquefied Gas). Official bulletin of copyrights 2017:45:212. 